\title{
Needs Around Dialysis Treatment from Different Perspectives (NADIP): Results of the Exploratory German Multicenter Survey
}

\author{
Patrick Biggar $^{\mathrm{a}}$ Dennis Hidde ${ }^{\mathrm{b}}$ Markus Ketteler ${ }^{\mathrm{a}}$ \\ aDivision of Nephrology, Klinikum Coburg, Coburg, Germany; ${ }^{b}$ AbbVie Deutschland GmbH \\ and Co. KG, Wiesbaden, Germany
}

\section{Keywords}

Chronic kidney disease - Quality of life · Patient-centered care · Renal replacement therapy · Caregivers

\begin{abstract}
Background/Aims: In 2015, approximately 70,000 patients with end-stage renal disease were treated chronically with dialysis in Germany. However, there is only sparse information regarding subjective appreciation of the different aspects of extracorporeal renal replacement therapies. This study was performed to gain insight into the needs and appreciation of services in dialysis centers in Germany including the views not only of the patients but also of the caregivers, physicians, and nurses. Methods: A cross-sectional written voluntary questionnaire survey based on the international RAND Kidney Disease Quality of Life Short Form (version 1.3) comprising 510 adult dialysis patients, 274 caregivers, 29 physicians, and 60 nurses in 30 dialysis centers across Germany. Results: Although patients were mostly satisfied with present treatment options, room for improvement exists. Patients were less critical of services than doctors and nurses. Factors such as trustworthy contact with staff at the centers as well as information exchange with other patients and among caregivers play a significant role in the patients' perception of a high-quality dialysis treatment facility. Therefore, continued cost saving, in particular regarding personnel, may subjectively counteract the objective technical improvements of dialysis. Conclusions: High-quality technical standards are essential for successful dialysis therapy; however, additionally, we recommend an array of communicative and social tools employed by all stakeholders to convey and exchange information and also support subjective well-being. This survey represents one of the largest evaluations to date. The data are also of potential international relevance for non-German health management systems.
\end{abstract}




\section{Kidney \\ Blood Pressure \\ Research}

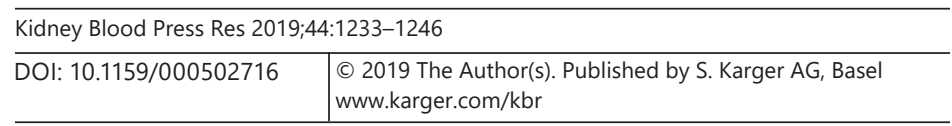

Biggar et al.: Survey of Caretaking Stakeholders in Dialysis

\section{Introduction}

In 2015, approximately 90,000 patients with end-stage renal disease were treated in Germany with hemodialysis (HD) or peritoneal dialysis (PD), of which 70,000 were treated chronically [1]. Parallel to technical advances in the last 40 years, nephrologists have witnessed a transition of patient expectation in everyday life from initial essential prolongation of life on dialysis in an otherwise terminal state of uremia to progressive self-determination of method also encompassing social and family integration. Not denying tremendous technical advances, further achievements must accommodate views and perceptions of all groups involved in caregiving.

Several analyses have focused on the needs of patients purely from a medical point of view and only considering insights gained solely from the patient [2, 3]. However, expert groups are becoming increasingly aware that information on the understanding of the impact of dialysis on a patient's life that is gained from different angles and perspectives can provide necessary new and profound insights to improve patient satisfaction [4, 5]. Successful implementation of kidney replacement therapy requires adequate education and participation of caregiver groups to facilitate shared decision-making regarding dialysis treatment options [6].

This is the first exploratory survey that provides comprehensive information and viewpoints of all major stakeholders involved in dialysis, that is, patients, physicians, nurses, and caregivers, documented and compared in a single cross-sectional investigation in Germany. In February 2019, in Germany, the dialysis sector comprised 53.8\% private practices, $27.8 \%$ institutional chain centers (i.e., Curatorium for Home Dialysis [KfH] 20.1\%, Patient Home Dialysis [Patienten Heimversorgung] 7.7\%), and a total of $18.4 \%$ commercial providers. Additionally in 2017, of a total of 1,942 hospitals, 327 supported a dialysis unit including 3 for the German Army offering a total of 3,605 dialysis stations [7]. Due to the internationally standardized design and the fundamental content of the questionnaire parameters, the intentional results may be extrapolated to non-German health systems.

Utilization of dialysis therapies other than standard HD is, in part, dependent on training experience of the doctors involved [8]. Thus, nephrology training programs should ensure that all trainees are prepared to offer all forms of dialysis. In this respect, studies analyzing subjective perception and acceptance of the methods can offer guidance with the intention of more successful implementation of renal replacement options.

\section{Material and Methods}

\section{Ethics}

The survey was planned and performed as a noninterventional, observational, crosssectional questionnaire study. Participation of the centers, professional personnel, and patients including their personal caretakers was essentially voluntary. Informed, written consent was mandatory for all participants. The exploratory survey was approved in 2014 by the Ethics Committee of the Doctors Medical Association, Munich, Germany. No additional diagnostic or monitoring procedures were applied to the patients; thus, an EU PASS Register Number was not required.

\section{Survey Design}

The survey was designed as multicenter, noninterventional, observational, and descriptive without influencing the regular treatment of patients in routine medical care. Information was collected in the form of written questionnaires based on the RAND (Research 
and Development) Institution Kidney Disease Quality of Life Short Form (SF 36 Health Assessment, version 1.3) and adapted accordingly to the specifically surveyed groups. To increase comprehensibility, satisfaction was rated using the German school mark system: that is, " 1 " for "very satisfied" to "6" for "not satisfied at all," as compared to the inverse RAND grading system with " 0 " indicating "worst possible" and "10" signifying "best possible health" [9].

The following parameters were analyzed descriptively and subjective impressions were compared:

1. Patient-specific items

- Impact of dialysis (patient vs. family member)

- Burden on family members (patient vs. family member)

- Contact and exchange of information (patient and family member)

- Patient satisfaction (respective of therapy method)

2. Center-specific items

- Relevance of services (doctor vs. nurse vs. patient)

- Grading of center (doctor vs. nurse vs. patient vs. family member)

- Potential of optimization in centers (doctor vs. nurse)

3. German flatrate cost compensation

- Potential effects on centers (doctor vs. nurse)

- Apprehensions of patients and family members

\section{Statistical Methods and Quality Control}

Information was collected in the form of a paper questionnaire distributed via AbbVie medical department to dialysis centers in Germany. The data collection period was from February 15, 2015, until October 31, 2015. A total of 43,549 single items were evaluated. AbbVie Deutschland GmbH and Co. KG and Primus Consulting Group GmbH Germany performed data quality control.

Data management was based on the guidelines and recommendations for ensuring Good Epidemiological Practice. Statistical analysis was performed using SPSS IBM Statistics 23 Windows and MAC and Microsoft Excel version 14.0.7145. As this survey was exploratory with no previous pertinent comparable analyses, there was no formal sample size calculation, and the statistical analysis was performed in a descriptive way by calculating means and SDs. Continuous data were computed using the number of patients $(n)$, mean, SD, median, minimum, and maximum. Categorical data were summarized by using number and percentages of patients. Analysis of variance (ANOVA) was utilized for group comparisons. Where appropriate, 2-sided Pearson's chi-square calculations were applied to comparisons between HD and PD. Additionally, $t$ testing of means and Levene-testing of homogeneity of variance were performed (data on file). Missing data were not substituted and, thus, were exempted from computation.

\section{Patients}

Participation and response to questions were strictly voluntary. Participants were eligible, if they were aged 18 years and over and had chronic kidney disease stage 5D. Participation was reimbursed to the centers according to the standard German Doctor tariff. 


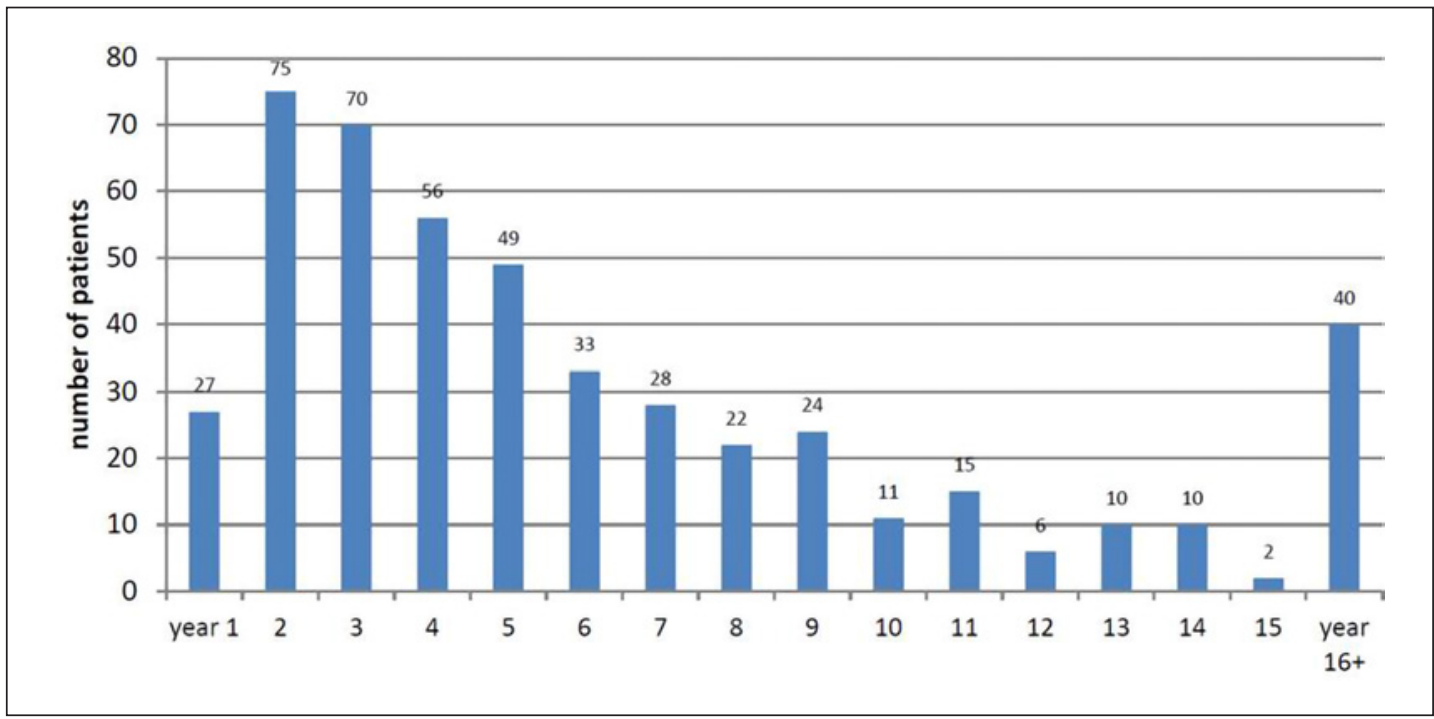

Fig. 1. Duration of dialysis therapy (all methods).

\section{Results}

The cross-sectional study was performed at 30 sites across Germany and included 510 adult dialysis patients (66 questions), 274 caregivers (23 questions), 29 physicians (43 questions), and 60 nurses (39 questions).

\section{Dialysis Centers}

In total, $66 \%$ constituted private dialysis centers, $14 \%$ represented hospital institutions, $10 \%$ were run by the "Patienten Heimversorgung," a nonprofit organization and $10 \%$ were supported by various other facilities. The largest proportion of patients were treated in centers catering for between 50 and 99 patients ( 9 centers); 2 centers supported $<50$ patients, 5 centers $100-149$ patients, 3 centers $150-199,5$ centers $200-299,1$ center $300-499$, and 1 center $>500$ patients.

\section{Patients}

Age was entered by range: $2.5 \%$ of the patients were $\leq 30$ years old, $46.5 \%$ were between 31 and 65 years old, and $50.8 \%$ were over 65 years (50.8\%). In total, $58.8 \%$ of the patients were reported male and $38.4 \%$ female gender.

Of reported dialysis methods, 341 (66.9\%) of the patients declared treatment with HD, 97 (19\%) with PD, and 9 (1.8\%) with home HD (HHD). Dialysis vintage ranged from first year on dialysis up to 44 years of dialysis therapy (Fig. 1).

At the time of the survey, $18.6 \%$ of patients were still professionally active, whereas $76.7 \%$ were not.

\section{Impact of Therapy on Quality of Life Parameters}

Pearson's chi-square analysis revealed a statistical significant effect of the dialysis method on professional activity with least burden incurred by PD ( $p=0.04$; Table 1$)$. Similarly, patients on PD reported less negative effects on recreational activity than HD patients (Pearson's chi-square $p=0.011$; Table 2). 
Table 1. Effect of dialysis modality on occupation $(1=$ minimal effect; 6 = drastic effect)
Table 2. Effect of dialysis modality on recreation $(1=$ minimal effect; 6 = drastic effect)

\begin{tabular}{lccl}
\hline Strength of effect & HD $n(\%)$ & PD $n(\%)$ & \multicolumn{1}{l}{ Total } \\
\hline 1 & $25(12.3)$ & $14(23.7)$ & $39(14.8)$ \\
2 & $23(11.3)$ & $8(13.6)$ & $31(11.8)$ \\
3 & $31(15.2)$ & $4(6.8)$ & $35(13.3)$ \\
4 & $25(12.3)$ & $12(20.3)$ & $37(14.1)$ \\
5 & $44(21.6)$ & $12(20.3)$ & $56(21.3)$ \\
6 & $56(27.5)$ & $9(15.3)$ & $65(24.7)$ \\
\hline Total & $204(100)$ & $59(100)$ & $263(100)$ \\
\hline
\end{tabular}

HD, hemodialysis; PD, peritoneal dialysis.

\begin{tabular}{lccc}
\hline Strength of effect & HD $n(\%)$ & PD $n(\%)$ & \multicolumn{1}{l}{ Total } \\
\hline 1 & $18(5.4)$ & $4(4.2)$ & $22(5.1)$ \\
2 & $34(10.2)$ & $23(24.0)$ & $57(13.3)$ \\
3 & $110(33.1)$ & $27(28.1)$ & $137(32.0)$ \\
4 & $83(25.0)$ & $23(24.0)$ & $106(24.8)$ \\
5 & $57(17.2)$ & $16(16.7)$ & $73(17.1)$ \\
6 & $30(9.0)$ & $3(3.1)$ & $33(7.7)$ \\
\hline Total & $332(100)$ & $96(100)$ & $428(100)$ \\
\hline
\end{tabular}

HD, hemodialysis; PD, peritoneal dialysis.

\section{Patient Satisfaction}

Mean patient satisfaction rates were generally high with 1.83 for HD, 1.53 for PD, and 1.89 for HHD. On the whole, patients' impression of their general health/vitality/well-being was mostly neutral (mean 2.98) with slightly worse ratings from their caregivers (mean 3.30). Specific visualization of single parameters showed a pronounced negative effect on sexuality as compared to only a modest effect on appetite (Fig. 2). Regarding PD, ANOVA showed a tendency toward superior general well-being $(p=0.051)$ and highly significant superiority of the item vitality $(p=0.015)$. The other sub-items did not reach statistical significance.

Possibly as expected, ANOVA revealed a significant association between age and health $(p<0.001)$ as well as age and vitality $(p=0.01)$. However, appetite was not specifically affected preferentially by the method of dialysis.

The burden of dialysis for the caregiver was typically perceived as higher seen from the viewpoint of the caregivers as compared to the patients' estimation of their burden on their caregivers (Fig. 3). Pearson's chi-square analysis did not show any significant difference between the dialysis methods.

\section{Informational Exchange between Patients}

Interestingly, only a small minority of patients and their caregivers felt that informational exchange and contact between patients was unimportant; $>1 / 3$ regarded exchange as important (Fig. 4). However, $76.0 \%$ of patients and $77.1 \%$ of care givers described rare or no contact in everyday practice, suggesting an area for future improvement by actively supporting informational exchange between patients. 


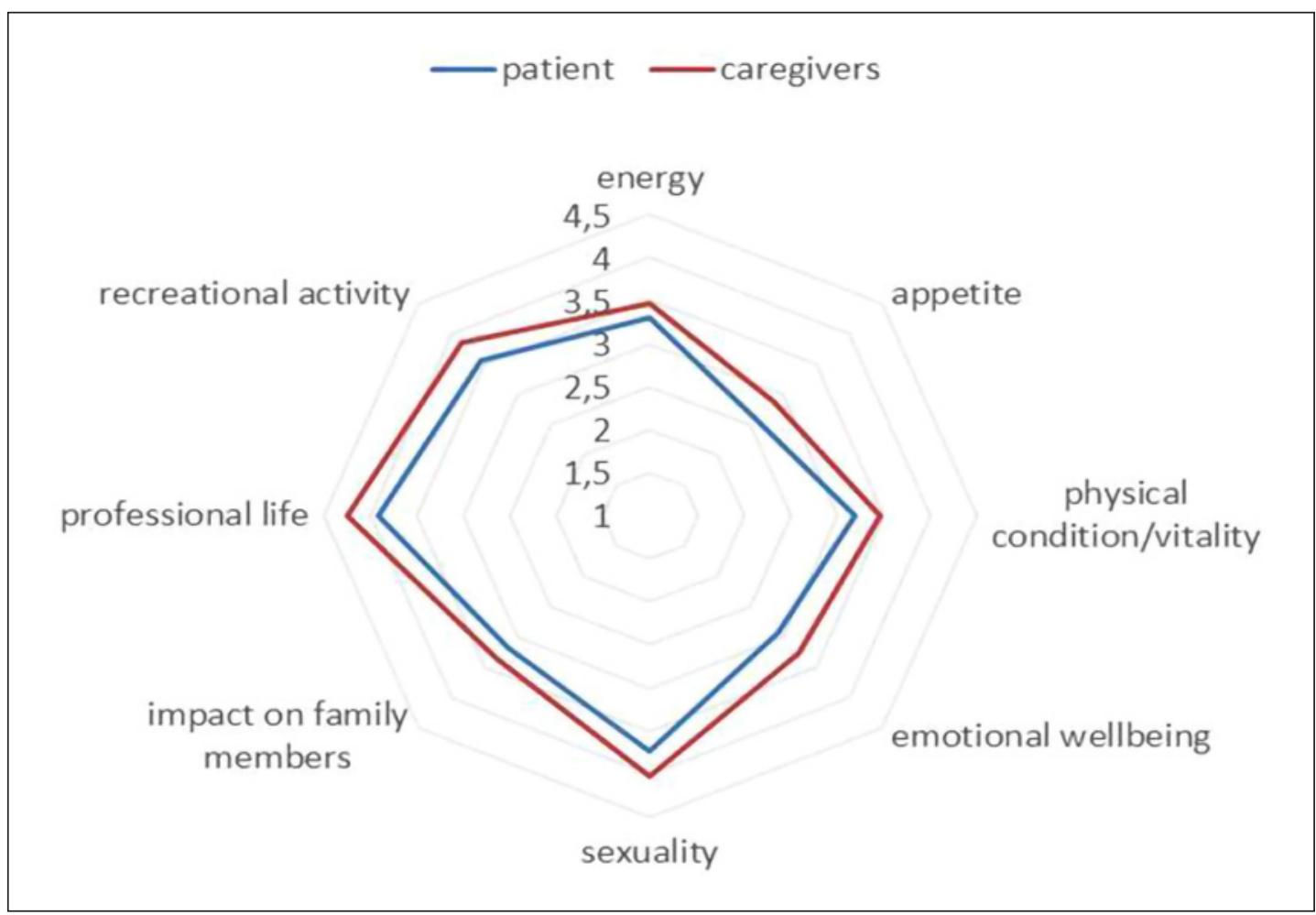

Fig. 2. Impact of dialysis on patient-specific quality of life parameters, patient versus caregivers $(1=$ no impact, 6 = strong impact).

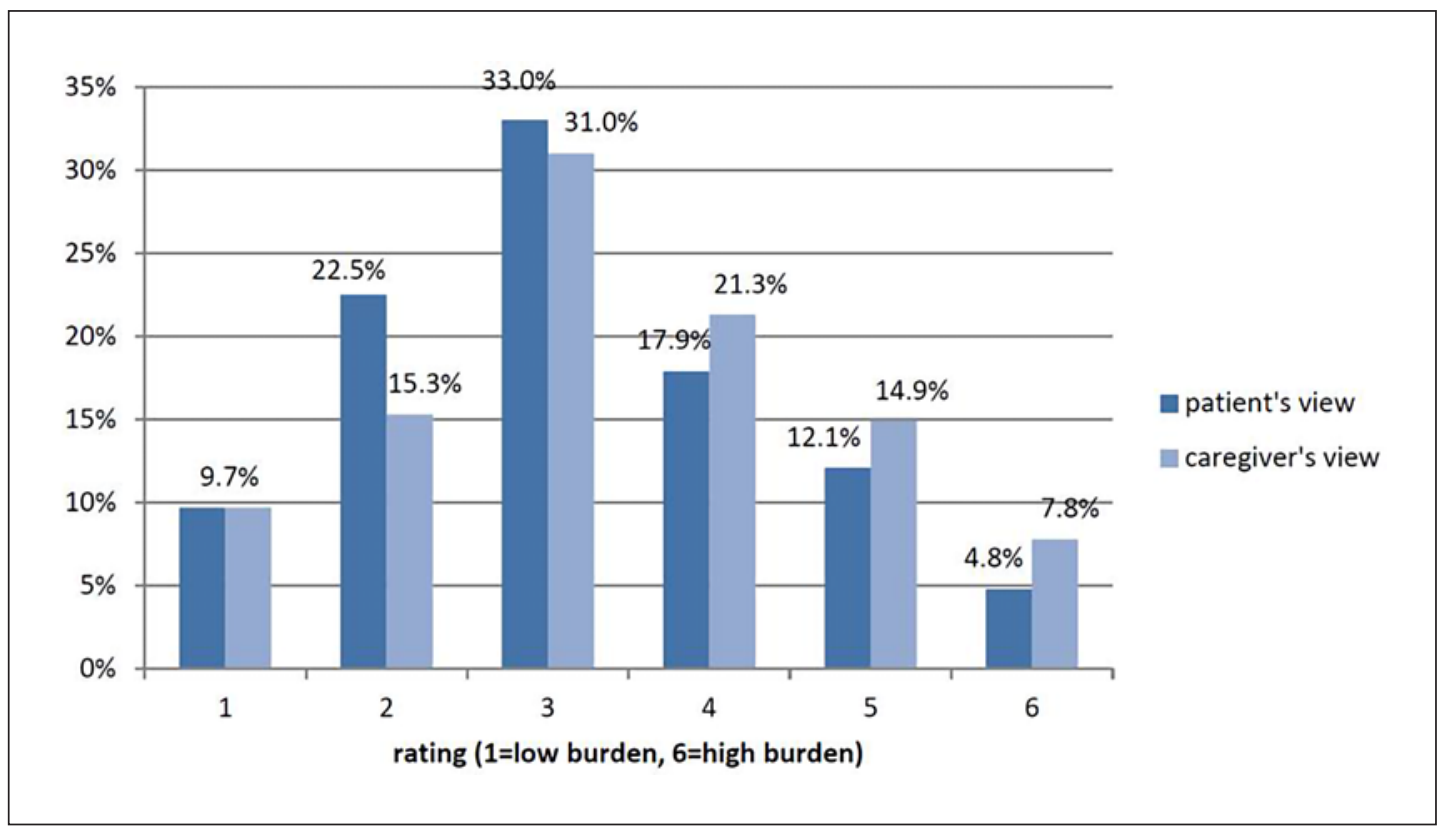

Fig. 3. Impact of dialysis on overall burden for the caregiver (patient vs. caregiver). 


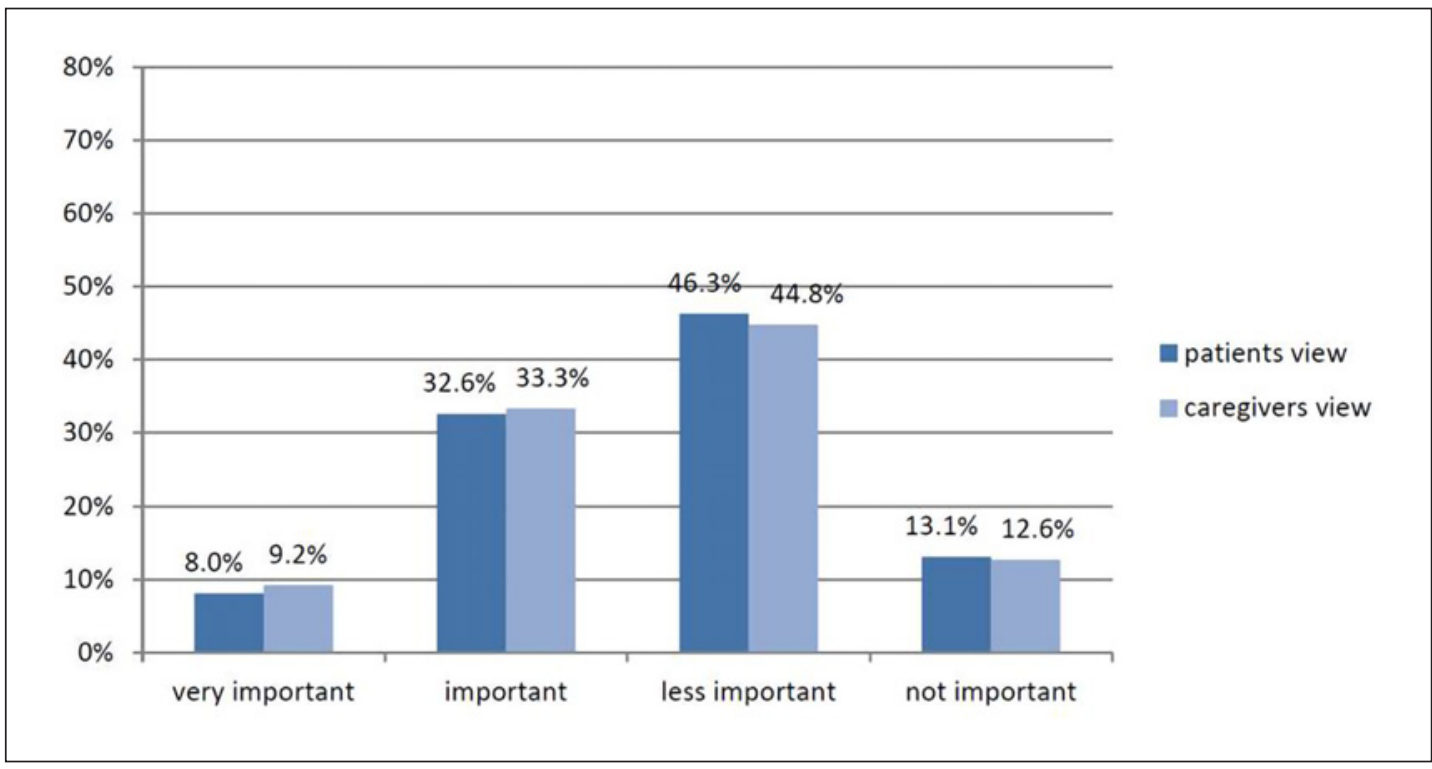

Fig. 4. Importance of informational exchange and contacts between patients (patients vs. caregivers, all dialysis methods).

\section{Informational Exchange between Caregivers}

A total of $32 \%$ of the caregivers rate this kind of contact as being (very) important, but only 5.9\% have at least regular actual contact with others (Fig. 5). This indicates that there might be an additional unmet need within the group of caregivers for support in establishing contacts to other caregivers.

\section{Dialysis Center Performance}

Single parameter analysis showed significant differences in appreciation of dialysis center services, with food and beverages approval ratings ranging far lower than flexibility of shifts and appointments. Remarkably, nurses generally had a worse impression of services and atmosphere than either patients or doctors (Fig. 6).

Nursing staff performance was generally well appreciated, whereas time availability was marked noticeably worse than, for example, expertise. Figure 7 shows the distribution of ratings from the patients versus doctors versus nurses. Here again, nurses' impressions were mainly worse than the judgment by the patients, with an intermediate appraisal by the doctors.

Regarding physicians' performance, doctors and nurses estimated that time availability was significantly inferior as compared to, for example, medical expertise. Remarkably, nurses, again, had a worse impression than either the doctors or patients. Interestingly, patients' estimation of physicians' time availability was appreciated far better than the perception of the other groups (Fig. 8).

\section{Counseling Services}

Laboratory analyses, medication, and treatment methods prior to initiation of renal replacement therapy were regarded as important counseling services as compared to change of treatment methods/modalities and psychological/social counseling. Patients and doctors marked the services on average with " 2 ," whereas the nurses' impression was again more 


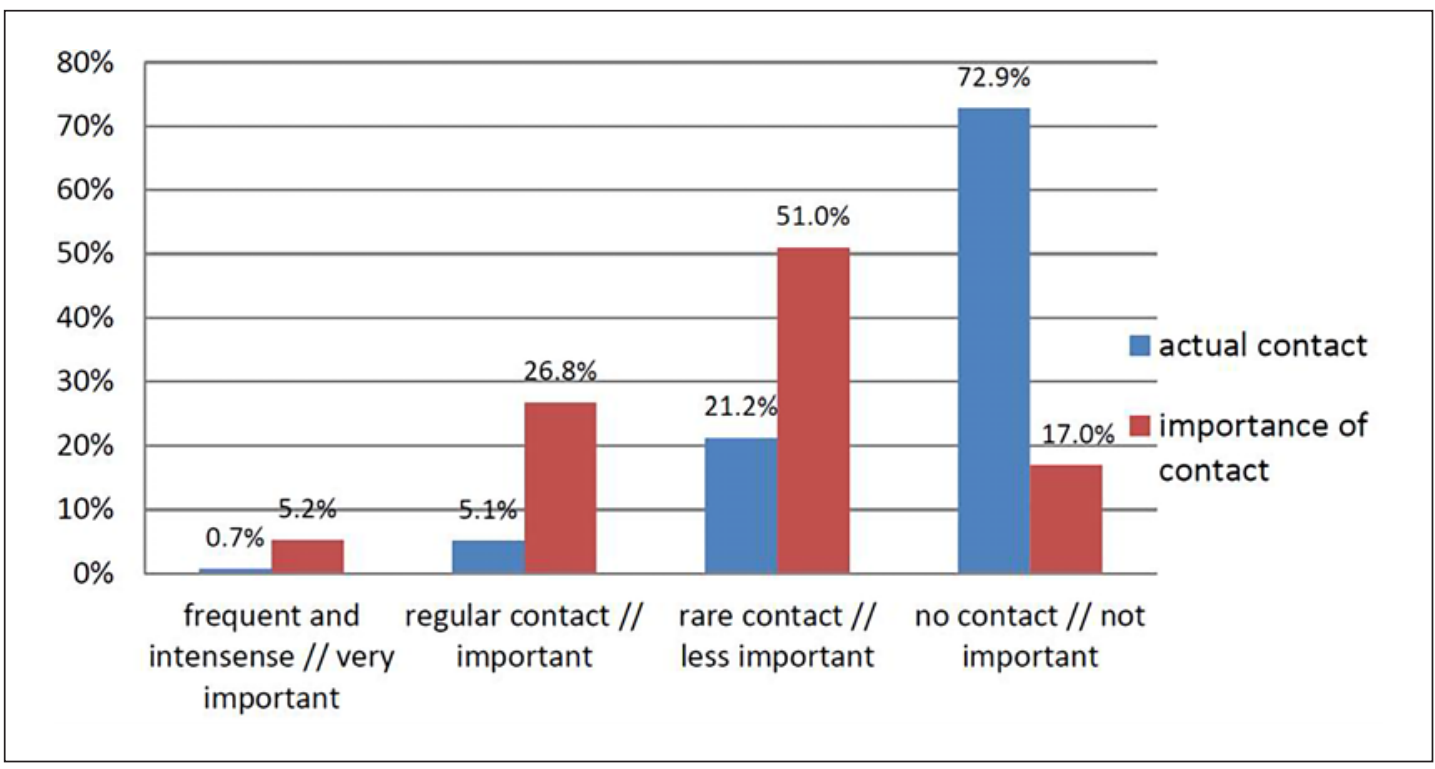

Fig. 5. Informational exchange and contact between caregivers.

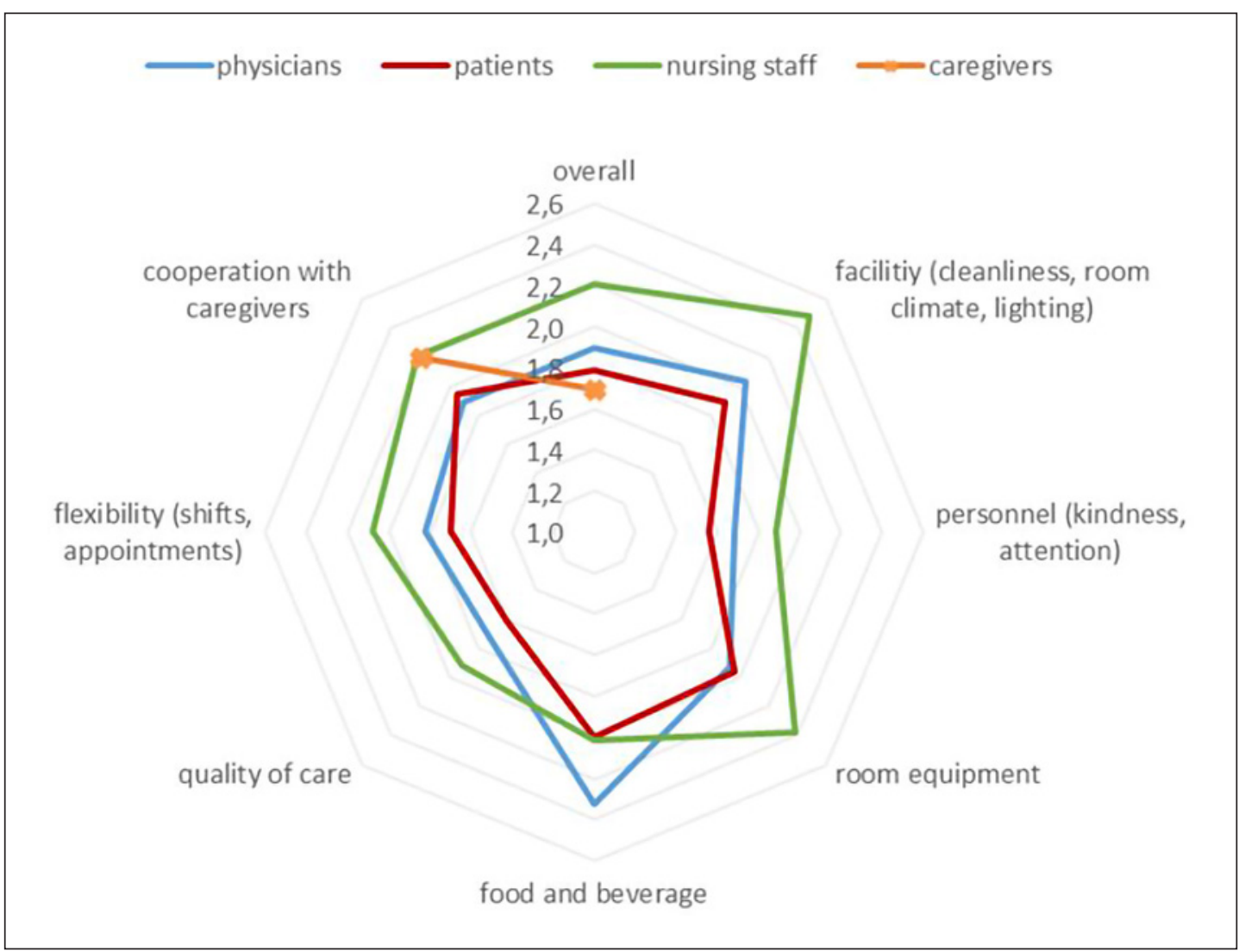

Fig. 6. Satisfaction of stakeholders regarding overall and specific dialysis center characteristics pertaining to impression/atmosphere ( 1 = very good, 6 = very bad). 


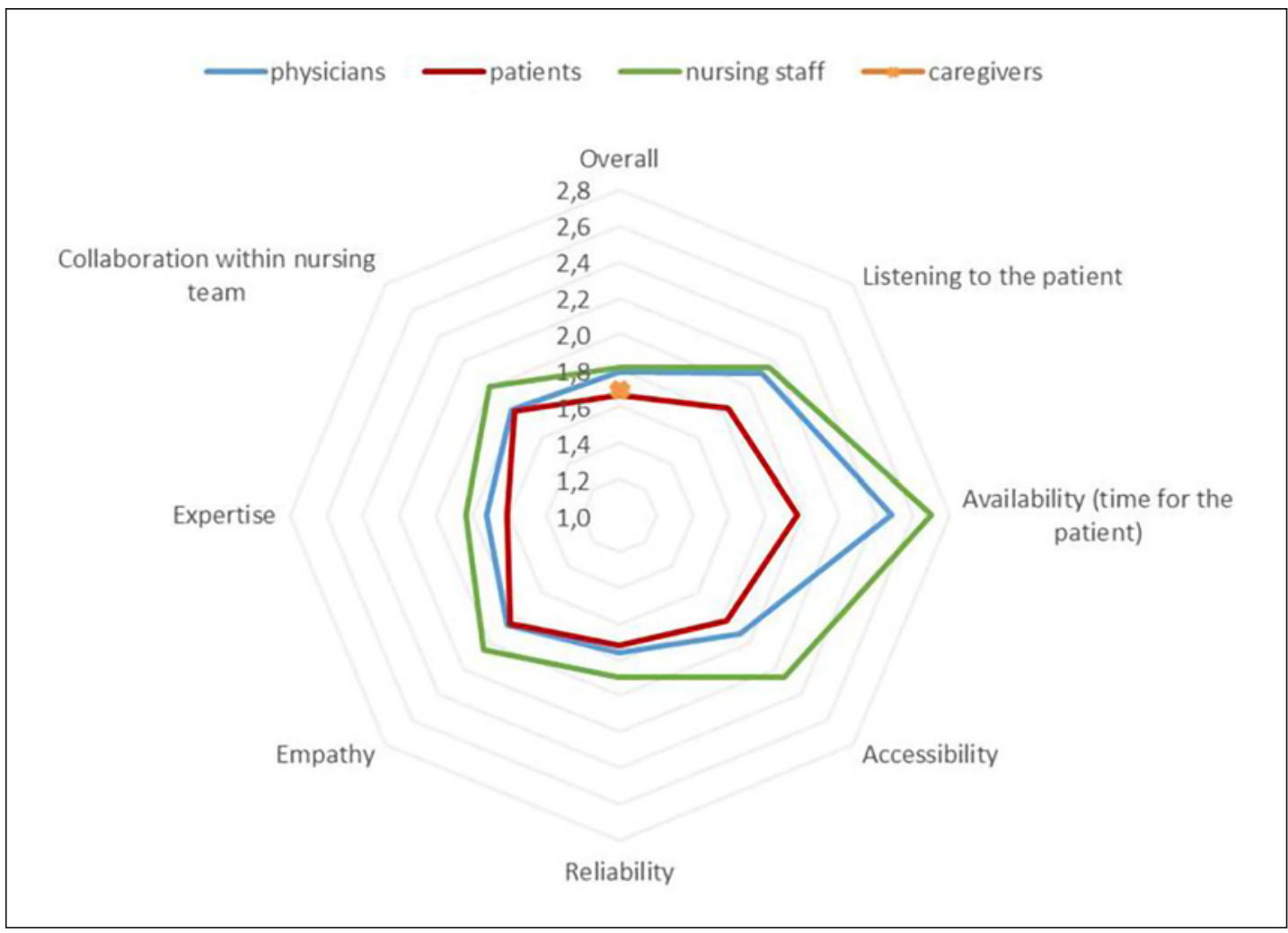

Fig. 7. Performance rating regarding nurse staff ( 1 = very good, $6=$ very bad $)$.

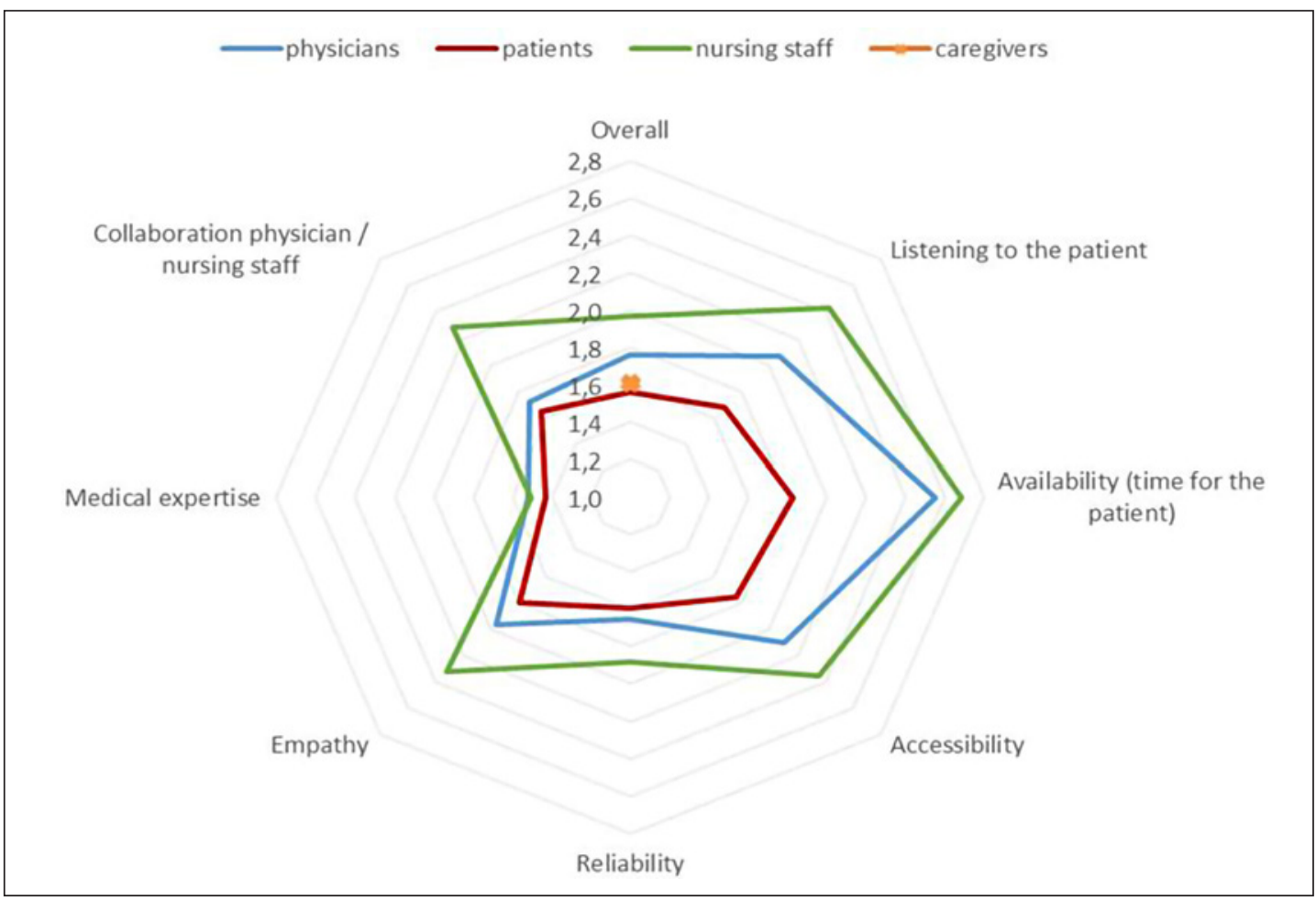

Fig. 8. Performance rating regarding physicians ( 1 = very good, $6=$ very bad). 


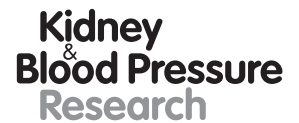

Kidney
Blood Pressure
Research

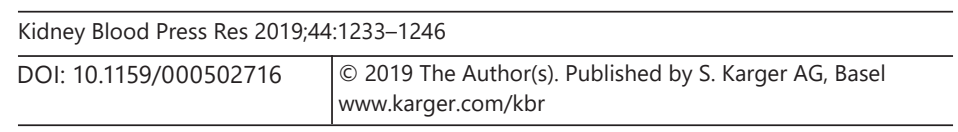

Biggar et al.: Survey of Caretaking Stakeholders in Dialysis

critical. Interestingly, patients' estimation of importance was nearly identical to their perception of performance in the dialysis centers, suggesting that the centers are delivering accordingly weighted services.

\section{Dialysis Method Reimbursement}

Taking into account that $39.4 \%$ of patients and $48.3 \%$ of caregivers had declared that they had no knowledge of dialysis reimbursement or potential future developments, $73.4 \%$ of patients and $77.2 \%$ of caregivers with knowledge feared negative consequences of recent and planned reimbursement changes on treatment and services at the dialysis centers and the consequence of potential cost sharing by the patient.

Nursing staff and physicians similarly feared a negative impact on services caused by economization (personnel, drugs, material), loss of quality (caretaking, flexibility, reduction in physicians/nurses), and organizational changes.

\section{Discussion}

The results presented in this cross-sectional, single approach survey are, so far, unique in that they offer insights into the similarities and differences between the perceptions of the major stakeholders concerning not only HD but also HHD and PD.

A comparison of our patient cohort characteristics showed several differences regarding demographics [10-14]. In our study, $58.8 \%$ of the participants were reported male being very similar to $57.2 \%$ demonstrated in the USRDS (United States Renal Data System) annual report for 2016, respectively, with $38.4 \%$ female genderversus $42.8 \%$ in the USA. A similar proportion is also reflected in the UK renal registry data.

In our study, $2.5 \%$ of the patients were $\leq 30$ years old as compared to $6.2 \%$ in the USA. In our cohort, 46.5\% were between 31 and 65 years old, whereas the USRDS Annual Report relating to 2016 describes 51.4\%. The UK Renal Registry Report 2018 pertaining to data collected in 2016 refers to $63.1 \%$ in the extended age group of 18-65 years. In total, $50.8 \%$ of our participants were older than 65 years; the respective numbers for 2016 were $46.3 \%$ in the USA and $36.9 \%$ in the UK reflecting a slightly older cohort in our study. However, on the German national level, the German Joint National Committee reported for 2015 that $36.6 \%$ were aged $18-64$ years and $63.4 \%$ older than 65 years [15]. Thus, our results are intermediate between German national and international publications.

Globally, the percentage of HHD treatment is low, $1.8 \%$ in our study, $0.67 \%$ generally in Germany, $4.3 \%$ in the UK, and $1.2 \%$ in the USA.

Regarding treatment modalities, $66.9 \%$ of our patients declared treatment with HD. German national registry data reported $93.7 \%$ on HD, whereas the respective percentage was $87 \%$ in 2016 in the UK and $87.8 \%$ in the USA. The corresponding number for PD was $19 \%$ in our study versus $5.5 \%$ on the German national level and $4.3 \%$ in the UK and $10 \%$ in the USA. The number of PD patients was intentionally increased in our study to enable a statistically meaningful comparison to the HD cohort. Although a higher percentage of PD patients could theoretically account for the increased demand for methodical information, this is not reflected in the data we collected and would not adequately explain the differences reported.

Comparative studies have often pertained to the impact of dialysis modality on healthrelated quality of life [16-18]. However, results have not been homogeneous, and a metaanalysis of 52 studies, comprising $>36,000$ patients, revealed no significant differences between dialysis modalities with respect to SF36 parameters [19]. Our study was specifically based on SF36, version 1.3 (RAND Institution), comprising questions pertinent to quality of life under present standard living conditions in Germany, thus enabling international compa- 


\section{Kidney \\ Blood Pressure \\ Research}

\begin{tabular}{l|l}
\hline Kidney Blood Press Res 2019;44:1233-1246 \\
\hline DOI: 10.1159/000502716 & $\begin{array}{l}\text { ○ 2019 The Author(s). Published by S. Karger AG, Basel } \\
\text { www.karger.com/kbr }\end{array}$ \\
\hline
\end{tabular}

Biggar et al.: Survey of Caretaking Stakeholders in Dialysis

rability. The questions were adapted to the targeted study groups, and the multiple aspects of patient satisfaction were allocated a proportionally larger coverage. The scoring system was inversely changed from the original SF36 range of 0-10 (worst to best) to 1-6 (best to worst) basing the written questionnaires on school marks well accepted and understood by all Germans. Thus, also in this respect general comparability to the original SF36 questionnaire is not significantly compromised.

The participants were distributed across Germany in various types of dialysis center institutions addressable by the Medical Department of AbbVie, thus reducing the influence of center-specific idiosyncrasies.

Average perception of well-being was estimated at a mediocre level of approximately 3 , demonstrating significant affliction. As with other parameters, the caregivers tended to describe slightly more marked impairment as compared to the patients themselves.

Regarding specific dialysis methods, PD patients described slightly better general and psychological health (2.71) as compared to HD (2.95), giving a similar impression to that described by Robinski et al. [20] in the German CORETH (Choice of Renal Replacement Therapy) study, which concentrated on patients perception. PD can offer patients a sense of independence. However, this depends heavily on minimizing fear and depression, both of which can be addressed positively in explanatory discussions between the doctor and the patient enabling the patient to reach a conclusion together with the doctor (shared decisionmaking) [21]. As with standard HD, comprehensive care service is required to reduce the risks of impaired self-esteem, physical incapacitation, and reduced social functioning including social support [22]. Strategies that aim at strengthening social support and promote confidence in patients are pivotal to achieving positive adjustment, improved psychosocial outcomes, and treatment satisfaction [23]. The findings of our study extend beyond the individual patient on dialysis and are comparable to studies pertaining to compliance to oral medication [24].

Our study also detected a discrepancy between the subjective need for informational exchange and contact between dialysis patients, with only $24 \%$ actually having regular contact, and a larger proportion of patients and caregivers ( $>40 \%)$, who considered it important or very important. This finding is remarkable as HD patients, who actually see other patients during their dialysis sessions on a regular basis, have less contact than would otherwise be expected based on the declared level of importance. Thus, it may be advantageous that dialysis centers support contact among patients as well as their caretaking relatives and provide information to include caregivers.

Undoubtedly, patient PD education affects final choice [25]. A systematic review demonstrated a strong association between patient-targeted education interventions and the subsequent choice and receipt of PD [26]. However, the relevance of additional caregiver information exchange may be evident considering the results of the Liebman et al. [27] study showing that of 217 patients receiving education and contemplating starting dialysis therapy, 124 initially chose PD, 52 were undecided, and 41 chose HD. However, final modality distribution at the time of effective dialysis therapy initiation was reversed with 150 on HD and 67 on PD. Of 124 patients who chose PD at the time of education, 59 actually started dialysis therapy with PD and 65 started with HD. On multivariable analysis, especially age older than 75 years and unemployment predicted starting with HD therapy. The study hypothesized that other factors are involved affecting patients' choice of therapy even after dialysis education [27]. Again, in this respect, our present study draws attention to the wider involvement of caregivers than previously appreciated.

It is noteworthy that HHD patients gave intermediate ratings of general and psychological health in our study (2.89). Arguably, the initial health status may have played a role in the final decision of renal replacement method and not necessarily vice versa. However, 


\section{Kidney \\ Blood Pressure \\ Research}

\begin{tabular}{l|l}
\hline Kidney Blood Press Res 2019;44:1233-1246 \\
\hline DOI: 10.1159/000502716 & $\begin{array}{l}\text { @ } 2019 \text { The Author(s). Published by S. Karger AG, Basel } \\
\text { www.karger.com/kbr }\end{array}$ \\
\hline
\end{tabular}

Biggar et al.: Survey of Caretaking Stakeholders in Dialysis

concerning satisfaction of the type of dialysis method, PD was rated slightly better than HD with HHD trailing in last position (1.53, respectively, 1.83 and 1.89). HHD patients are generally the healthiest and most independent, again implying that other factors other than initial health restraints are involved.

Patients without direct experience in HHD and their caregivers may recognize the autonomy of HHD but are generally concerned about the potential burden and personal sacrifice HHD will impose on caregivers, also feeling apprehensive about accepting the medical responsibility for dialysis. Our results support previously published views that promoting acceptance of HHD requires effective strategies providing information and facilitating peer patient support [28] additionally to financial support particularly for those residing in remote areas [29]. Seshasai et al. [30] demonstrated in a cohort of 2,840 patients that diabetes and smoking/alcohol/drug use were associated with an increased risk for HHD discontinuation (hazard ratios 1.34 [95\% CI 1.07-1.68] and 1.34 [95\% CI 1.01-1.78], respectively), underlining the complexity of the mechanisms involved in decision taking and method maintenance.

Our results compliment the findings of the Empowering Patients on Choices for Renal Replacement Therapy study comprising telephone interviews of 179 patients regarding coping strategies in HD and PD [5]. Subramanian reanalyzed these findings in respect to personal patient-coping responses, implying that more engagement than disengagement strategies were observed. "Take care of myself and follow doctors' orders," "accept it," and "rely on family and friends" were the common coping themes with participants often using multiple coping strategies [31].

Furthermore, Kopple et al. [32] have described the resulting stress in 246 maintenance HD patients utilizing the Beck Anxiety Inventory and Beck Depression Inventory. Whilst Kopple et al. [32] concentrate exclusively on patients' degrees of anxiety with no apparent decrease over time, Subramanian extends the patients horizon to families and friends, however, again without analyzing directly the perception of all the caregivers involved. Furthermore, both studies are restrictive in suggesting practical supportive coping options.

In our present study, patients rated physician and nursing care at the dialysis centers as good and were satisfied with services provided. Nurses are slightly more critical of the services provided at the dialysis centers than the patients, whereas all groups saw room for improvement. Concerns were raised by physicians and particularly nursing staff concerning publicly discussed changes in the reimbursement scheme ("Sachkostenpauschale" - translated as "lump sum payment scheme") impacting on organization and treatment quality at the dialysis center.

Personal contact and attendance by physician and nurses played a significant role for the patients receiving better marks than the facility and treatment itself. Patients voted that psychological counseling and help with social welfare are relatively important, thus supporting improvement in this area.

All decisions rely on personal contact and trust. Within a larger scenario of high mortality after starting dialysis, improved preparation for end-stage kidney disease is needed to respect patient and family choices also enabling timely initiation and refusal or discontinuation of dialysis [33]. Urquhart-Secord et al. [34] have analyzed that the top 10 outcomes as ranked by patients on a scale of 1 for unimportant to 10 as very important were fatigue/energy (mean rank score, 4.5), survival quality defined by patients as resilience and coping (3.7), ability to travel (3.6), dialysis-free time (3.3), impact on family (3.2), ability to work (2.5), sleep (2.3), anxiety/stress (2.1), decrease in blood pressure (2.0), and lack of appetite/taste (1.9). Mortality ranked only 14th and was not regarded as the complement of survival. However, caregivers ranked mortality, anxiety, and depression higher than patients, whereas patients ranked ability to work higher [34], underlining the necessity for informational exchange on multiple levels. 
A weakness of our study was unavailability of participation of the KfH Dialysis Institution, Germany, which supports approximately $1 / 3$ of dialysis patients in Germany. However, the number of participants (510) is significantly larger than in many previous studies. A further unique strength is the inclusion of multiple stakeholders and very liberal inclusion criteria with few exclusions truly reflecting patients in real-world situations.

Overall, the study revealed that medical aspects of the dialysis treatment are of high importance for the patient's physical condition. However, factors such as a close and trustful contact with physicians and nursing staff at the center as well as informational exchange with other patients and among caregivers play a significant role in the treatment of dialysis patients. Continued cost savings, in particular on personnel, may counteract technical improvements of dialysis medicine.

Although the survey was performed in Germany, the character and implications of the evaluation enable extrapolation also to non-German health systems.

\section{Acknowledgments}

The authors gratefully acknowledge all the investigators, personnel, and patients including their caregivers for their contribution to the study. They also thank Dr. Hans-Peter Walther, Primus Consulting Group, Fraunhoferstrasse 15, 82152 Martinsried, Deutschland, for his assistance with statistics and evaluation, funded by AbbVie.

\section{Disclosure Statement}

P.B. and M.K. have received speaker and advisory honoraries from AbbVie Deutschland GmbH and Co. KG. D.H. is an employee of Abbvie Deutschland GmbH and Co. KG.

\section{Funding Source}

The design, study conduct, and financial support for the study were provided by AbbVie. AbbVie participated in the interpretation of data, review, and approval of the publication.

\section{References}

1 Medical Netcare Gmb H. Jahresbericht Datenanalyse Dialyse für den Gemeinsamen Bundesausschuss, Berichtsjahr 2015. [last accessed December 20, 2016]. Available from: www.medical-netcare.de/qsd.php.

2 Tong A, Henning P, Wong G, McTaggart S, Mackie F, Carroll RP, et al. Experiences and perspectives of adolescents and young adults with advanced CKD. Am J Kidney Dis. 2013 Mar;61(3):375-84.

3 Robinski M, Mau W, Lamprecht J, Krauth C, Girndt M. The Choice of Renal Replacement Therapy (CORETH) project: study design and methods. Clin Kidney J. 2014 Dec;7(6):575-81.

4 Finkelstein FO, Story K, Firanek C, Mendelssohn D, Barre P, Takano T, et al. Perceived knowledge among patients cared for by nephrologists about chronic kidney disease and end-stage renal disease therapies. Clin J Am Soc Nephrol. 2009;4(1):33-8.

5 Dahlerus C, Quinn M, Messersmith E, Lachance L, Subramanian L, Perry E, et al. Patient Perspectives on the Choice of Dialysis Modality: Results From the Empowering Patients on Choices for Renal Replacement Therapy (EPOCH-RRT) Study. Am J Kidney Dis. 2016 Dec;68(6):901-10.

6 Harwood L, Clark AM. Understanding pre-dialysis modality decision-making: A meta-synthesis of qualitative studies. Int J Nurs Stud. 2013 Jan;50(1):109-20.

7 German Federal Health Report 2017, Dialysis units, http://www.gbe-bund.de/oowa921-install/servlet/ oowa/aw92/dboowasys921.xwdevkit/xwd_init?gbe.isgbetol/xs_start_neu/\&p_aid=3\&p_aid= 41786870 \&nummer=678\&p_sprache=D\&p_indsp=-\&p_aid=95363180. 
Biggar et al.: Survey of Caretaking Stakeholders in Dialysis

8 Merighi JR, Schatell DR, Bragg-Gresham JL, Witten B, Mehrotra R. Insights into nephrologist training, clinical practice, and dialysis choice. Hemodial Int. 2012 Apr;16(2):242-51.

9 RAND Kidney Disease Quality of Life KDQOL 1.3/1997. [last accessed October 11, 2017]. Available from: https://www.rand.org/health/surveys_tools/kdqol.html.

10 German Federal Health Report 2016. [last accessed February 24, 2019]. Available from: http://www. gbe-bund.de/oowa921-install/servlet/oowa/aw92/dboowasys921.xwdevkit/xwd_init?gbe.isgbetol/xs_ start_neu/\&p_aid=i\&p_aid=58875271\&nummer=427\&p_sprache=D\&p_indsp=99999999\&p_aid=41955198, in German.

11 German Federal Health Report 2016. [last accessed February 24, 2019]. Available from: http://www. gbe-bund.de/oowa921-install/servlet/oowa/aw92/dboowasys921.xwdevkit/xwd_init?gbe.isgbetol/xs_ start_neu/\&p_aid=3\&p_aid=58875271\&nummer=878\&p_sprache=D\&p_indsp=-\&p_aid=85139172, in German.

12 Quasi-Nieren Bericht. 2008 (Qualitätssicherung in der chronischen Nierenersatztherapie). [last accessed February 24, 2019]. Available from: http://www.bundesverband-niere.de/fileadmin/user_upload/QuaSiNiere-Bericht_2006-2007.pdf, in German.

13 USRDS annual report 2018. [last accessed February 24, 2019]. Available from: https://www.usrds.org/adr.aspx.

14 UKAnnual RenalRegistry Report. Available from: https://www.renalreg.org/reports/2017-twentieth-annualreport/Nephron 2018; 139 (suppl 1).

15 Jahresbericht 2015 zur Qualität in der Dialyse, 31.03.2016. [last accessed February 24, 2019]. Available from: https://www.g-ba.de/downloads/39-261-3024/2017-07-20_QSD-RL_MNC-Jahresbericht-2016.pdf.

16 Steele TE, Baltimore D, Finkelstein SH, Juergensen P, Kliger AS, Finkelstein FO. Quality of life in peritoneal dialysis patients. J Nerv Ment Dis. 1996 Jun;184(6):368-74.

17 Carmichael P, Popoola J, John I, Stevens PE, Carmichael AR. Assessment of quality of life in a single centre dialysis population using the KDQOL-SF questionnaire. Qual Life Res. 2000 Mar;9(2):195-205.

18 Majkowicz M, Afeltowicz Z, Lichodziejewska-Niemierko M, Debska-Slizien A, Rutkowski B. Comparison of the quality of life in hemodialysed (HD) and peritoneally dialysed (CAPD) patients using the EORTC QLQ-C30 questionnaire. Int J Artif Organs. 2000 Jul;23(7):423-8.

19 Liem YS, Bosch JL, Arends LR, Heijenbrok-Kal MH, Hunink MG. Quality of life assessed with the Medical Outcomes Study Short Form 36-Item Health Survey of patients on renal replacement therapy: a systematic review and meta-analysis. Value Health. 2007 Sep-Oct;10(5):390-7.

20 Robinski M, Mau W, Wienke A, Girndt M. The Choice of Renal Replacement Therapy (CORETH) project: dialysis patients' psychosocial characteristics and treatment satisfaction. Nephrol Dial Transplant. 2017 Feb;32(2): 315-24.

21 Robinski M, Mau W, Girndt M. Wann sind Peritoneal- und Hämodialysepatienten mit ihrer Behandlung zufrieden? [in German]. Nephrologe. 2016;11(3):211-2.

22 Chanouzas D, Ng KP, Fallouh B, Baharani J. What influences patient choice of treatment modality at the predialysis stage? Nephrol Dial Transplant. 2012 Apr;27(4):1542-7.

23 Tong A, Lesmana B, Johnson DW, Wong G, Campbell D, Craig JC. The perspectives of adults living with peritoneal dialysis: thematic synthesis of qualitative studies. Am J Kidney Dis. 2013 Jun;61(6):873-88.

24 Van Camp YP, Vrijens B, Abraham I, Van Rompaey B, Elseviers MM. Adherence to phosphate binders in hemodialysis patients: prevalence and determinants. J Nephrol. 2014 Dec;27(6):673-9.

25 Mendelssohn DC, Mujais SK, Soroka SD, Brouillette J, Takano T, Barre PE, et al. A prospective evaluation of renal replacement therapy modality eligibility. Nephrol Dial Transplant. 2009 Feb;24(2):555-61.

26 Devoe DJ, Wong B, James MT, Ravani P, Oliver MJ, Barnieh L, et al. Patient Education and Peritoneal Dialysis Modality Selection: A Systematic Review and Meta-analysis. Am J Kidney Dis. 2016 Sep;68(3):422-33.

27 Liebman SE, Bushinsky DA, Dolan JG, Veazie P. Differences between dialysis modality selection and initiation. Am J Kidney Dis. 2012 Apr;59(4):550-7.

28 Tong A, Palmer S, Manns B, Craig JC, Ruospo M, Gargano L, et al. The beliefs and expectations of patients and caregivers about home haemodialysis: an interview study. BMJ Open. 2013 Jan;3(1):e002148.

29 Walker RC, Howard K, Morton RL, Palmer SC, Marshall MR, Tong A. Patient and caregiver values, beliefs and experiences when considering home dialysis as a treatment option: a semi-structured interview study. Nephrol Dial Transplant. 2016 Jan;31(1):133-41.

30 Seshasai RK, Mitra N, Chaknos CM, Li J, Wirtalla C, Negoianu D, et al. Factors Associated With Discontinuation of Home Hemodialysis. Am J Kidney Dis. 2016 Apr;67(4):629-37.

31 Subramanian L, Quinn M, Zhao J, Lachance L, Zee J, Tentori F. Coping with kidney disease - qualitative findings from the Empowering Patients on Choices for Renal Replacement Therapy (EPOCH-RRT) study. BMC Nephrol. 2017 Apr;18(1):119.

32 Kopple JD, Shapiro BB, Feroze U, Kim JC, Zhang M, Li Y, et al. Hemodialysis treatment engenders anxiety and emotional distress. Clin Nephrol. 2017 Oct;88(10):205-17.

33 Robinson BM, Akizawa T, Jager KJ, Kerr PG, Saran R, Pisoni RL. Factors affecting outcomes in patients reaching end-stage kidney disease worldwide: differences in access to renal replacement therapy, modality use, and haemodialysis practices. Lancet. 2016 Jul;388(10041):294-306.

34 Urquhart-Secord R, Craig JC, Hemmelgarn B, Tam-Tham H, Manns B, Howell M, et al. Patient and Caregiver Priorities for Outcomes in Hemodialysis: An International Nominal Group Technique Study. Am J Kidney Dis. 2016 Sep;68(3):444-54. 